\title{
CORRIGENDUM
}

\section{Dietary intake, glucose metabolism, and sex hormones in women with polycystic ovary syndrome (PCOS) compared with women with non-PCOS-related infertility - CORRIGENDUM}

Ya-Hui Tsai, Ting-Wen Wang, Hsiao-Jui Wei, Chien-Yeh Hsu, Hsin-Jung Ho, Wen-Hua Chen, Robert Young, Chian-Mey Liaw and Jane C.-J. Chao

(First published online 20 March 2014)

doi: 10.1017/\$0007114512004369, Published by Cambridge University Press, 9 October 2012.

The final sentence in the first paragraph on page 2194 of Tsai et $a l .{ }^{(1)}$ was mistaken regarding the results for the relationship between FAI and fat intake $(\mathrm{g} / \mathrm{d})$ corresponding to Table 3 . The statement should have been FAI was negatively associated with fat intake $(\mathrm{g} / \mathrm{d})(r-0 \cdot 15 ; P=0.048)$ in the control group.

The authors apologise for this error.

\section{Reference}

1. Tsai Y-H, Wang T-W, Wei H-J, et al. (2013) Changes in dietary intake, glucose metabolism, and sex hormones in women with polycystic ovary syndrome (PCOS) compared with women with non-PCOS-related infertility. Br J Nutr 109, 2190-2198. Published by Cambridge University Press, 9 October 2012, doi: 10.1017/S0007114512004369. 